\title{
Quantitative evaluation and analysis on the coordinated development of the urbanization and ecological environment in Xining city
}

\author{
JUN YE \\ Qinghai Institute of Environmental Science Research and Design
}

\begin{abstract}
Taking Xining City as the research area, the index system of coordinated development of urbanization and ecological environment in Xining City is constructed by combining qualitative and quantitative methods. The index and comprehensive index scores are obtained by using analytic hierarchy process and weighted summation method, and the coordination degree between urbanization and ecological environment in Xining City whose evolution trend is evaluated and analyzed is quantified by combining the coordination degree model. The results show that the urbanization level of Xining has been on the rise in the past 10 years from 2008 to 2017, and after the urbanization level of Xining has been improved, the eco-environmental quality index, although which has a characteristics of fluctuation, has been also on the rise as a whole. From the analysis of coordination degree, the coordination degree showed a downward trend year by year from 2008 to 2012, in which the coordination value in 2010, 2011 and 2012 were below 0.4, showing a moderate imbalance state; from 2013 to 2017, the coordination degree showed a rising trend year by year, and showed a relatively stable state.
\end{abstract}

\section{Introduction}

Urbanization is also called City and town-rization in China. It means that with the development of social productivity, the progress of science and technology and the adjustment of industrial structure in a country or region, its society has changed from a traditional rural society dominated by agriculture to a modern city dominated by non-agricultural industries such as industry (secondary industry) and service industry (tertiary industry). The historical process of the gradual transformation of the type society.[1]. But while urbanization promotes economic development, it also makes the ecological environment pay an irreversible price. In recent years, the urbanization construction of Xining City is fast. The built area of Xining City has expanded from $57.17 \mathrm{~km} 2$ in 2002 to $90.00 \mathrm{~km} 2$ in 2017. It is estimated that by 2030, the planned area of Xining City will reach $196.84 \mathrm{~km} 2[2,3]$. The annual increase of urban population indicates that Xining City has gradually entered the stage of rapid urbanization. However, there will be an inevitably conflict between the development of rapid urbanization and the ecological environment such as water, atmosphere, land and biology. The increasingly scarce resources and increasingly highlighted environmental problems have become the constraints of urban development. Therefore, how to coordinate the construction and development of urbanization and ecological environment has become the urgent task of the sustainable urban economic and social environment. development [4].

Through the construction of coordinated development model, we analysis the coordination status of Xining's urbanization and ecological environment compound system, and provide the main theoretical basis for promoting Xining to build a national innovative pilot city and promote sustainable development. Through quantitative analysis of the urbanization and ecological environment construction in Xining from 2008 to 2017, the relationship between urbanization and ecological environment is clearly understood, so as to provide suggestions for the harmonious development of urbanization and ecological environment in Xining, promote the sustainable development of Xining, and promote the construction of Xining as a national innovative pilot city.

\section{Material and Methods}

\subsection{Data Sources and Standardization Processing}

The research data mainly come from China's Urban Statistical Yearbook (2007-2017), Xining Statistical Yearbook (2007-2017), Xining Environmental Status Bulletin (2007-2017), Xining National Economic and Social Development Statistics Bulletin (2007-2017), Xining's 12th Five-Year Plan for Environmental Protection and Xining's 13th Five-Year Plan for 
Environmental Protection. " Environmental protection planning, in order to eliminate the influence caused by the difference of magnitude and dimension of data, requires standardized data processing [5], the formula is:

$$
Z_{i j}=\frac{x_{i j}-\min \left(x_{j}\right)}{\max \left(x_{j}\right)-\min \left(x_{j}\right)}
$$

In the formula: I is the year; $\mathrm{J}$ is the index serial number; $x$ is the index data. In order to unify the change direction of indexes, some indexes need to be processed by changing direction. The formula of changing direction processing is $\mathrm{zij}=1-\mathrm{Zij}$. After processing, the value range of data is between [0-1].

\subsection{Research methods and processes}

\subsubsection{Establishment of Evaluation Index System}

Based on the conceptual model of PSR, which was put forward by the Organization for Economic Cooperation and Development (OECD) and the United Nations Environment Programme (UNEP) at the end of 1980s, this paper establishes an index system reflecting the comprehensive development level of the ecological environment from three levels, namely, the pressure of the ecological environment, the state of the ecological environment and the response of the ecological environment. After standardization, the hierarchical analysis method and Delphi method (also known as expert consultation method) are used for hierarchical assignment to determine the weights of each level and index (Table 1)

Table.1 Integrated evaluation index system of urbanization and eco-environment in Xining city

\begin{tabular}{|c|c|c|c|c|c|}
\hline & Target Level & Criteria Level & weight & Index Layer & weight \\
\hline & & $\begin{array}{l}\text { Population } \\
\text { urbanization }\end{array}$ & 0.0418 & $\begin{array}{l}\text { he proportion of non-agricultural population in the total population is } \\
\qquad a_{1} / \%\end{array}$ & 0.7500 \\
\hline & & P11 & & The proportion of tertiary industry employment is $\mathrm{a}_{2} / \%$ & 0.2500 \\
\hline & & & & Fixed Assets Investment in the Whole Society $\mathrm{a}_{3} / 10,000$ Yuan & 0.1590 \\
\hline & & & & GDP growth rate $a_{4} / \%$ & 0.0323 \\
\hline & & & & Per capita GDP $a_{5} / y u a n$ & 0.0797 \\
\hline & & Urbanization & 01307 & Per capita local fiscal revenue $\mathrm{a}_{6} / \mathrm{yuan}$ & 0.0818 \\
\hline & & P12 & (0.1. & Gross industrial output value $a_{7} / 10,000$ yuan & 0.0478 \\
\hline & & & & The proportion of tertiary industry in GDP $\mathrm{a}_{8} / \%$. & 0.4148 \\
\hline & Urbanization & & & The proportion of industry in the total output value of industry and & 0.1846 \\
\hline & Subsystem & & & agriculture $\mathrm{a}_{9} / \%$. & \\
\hline & D1 & Spatial & & Urban area $\mathrm{a}_{10} / \mathrm{km} 2$ & 0.1884 \\
\hline & & Urbanization & 0.1721 & Area of built-up area $\mathrm{a}_{11} / \mathrm{km} 2$ & 0.7306 \\
\hline & & $\mathrm{P} 13$ & & Per capita paved road area $\mathrm{a}_{12} / \mathrm{m} 2$ & 0.0810 \\
\hline Compound Degree & & & & Water use penetration rate of urban population $\mathrm{a}_{13} / \%$ & 0.3458 \\
\hline of Urbanization & & & & Urban gas penetration rate $\mathrm{a}_{14} / \%$ & 0.0979 \\
\hline and Urban & & & & The number of public buses per 10,000 people $a_{15} /$ set & 0.0316 \\
\hline Ecological & & Urhanizatio & 01554 & Number of health facilities per 10,000 people $a_{16} /$ individual & 0.2177 \\
\hline Environment D. & & P14 & דנכוס & The expenditure of local finance on education $\mathrm{a}_{17} / 10000$ yuan & 0.0518 \\
\hline & & & & The number of university students in the city $\mathrm{a}_{18} /$ person & 0.0295 \\
\hline & & & & Average annual wage of on-the-job workers $a_{19} / y u a n$ & 0.1598 \\
\hline & & & & Total retail sales of consumer goods amounted to 20 billion yuan & 0.0659 \\
\hline & & & & Crop sowing area $b_{1} / h m 2$ & 0.1260 \\
\hline & & ntal level P21 & 0.1638 & Per capita public green space area $b_{2 / m} 2$ & 0.4161 \\
\hline & & & & Green coverage of built-up area $b_{3} / \%$ & 0.4579 \\
\hline & & & & Per capita daily water consumption $\mathrm{b}_{4} / \mathrm{L}$ & 0.1744 \\
\hline & & Eco-environme & & Sewage discharge $b_{5} / * 10^{4} \mathrm{~m} 3$ & 0.4289 \\
\hline & ment & ntal Pressure & 0.1299 & Agricultural fertilizer use $b_{6} / t$ & 0.2644 \\
\hline & Subort & $\mathrm{P} 22$ & & Industrial solid waste production $b_{7} / 10000 t$ & 0.0834 \\
\hline & $\begin{array}{ll}\text { De } \\
\text { D2 }\end{array}$ & & & Emissions of industrial smoke (powder) dust $b_{8} / 10000 t$ & 0.0489 \\
\hline & & & & Centralized treatment rate of municipal wastewater $\mathrm{b}_{9} / \%$ & 0.3009 \\
\hline & & Len-cin & & Industrial wastewater discharge up to standard rate $b_{10} / \%$ & 0.1557 \\
\hline & & Management & 0.2063 & Harmless treatment rate of municipal solid waste $b_{11} / \%$ & 0.1939 \\
\hline & & P23 & & Comprehensive utilization rate of industrial solid waste $b_{12} / \%$ & 0.1558 \\
\hline & & 123 & & Excellent rate of ambient air quality $\mathrm{b}_{13} / \%$ & 0.1939 \\
\hline
\end{tabular}

\subsubsection{Urbanization and Comprehensive Development Level of Ecological Environment}

The comprehensive development index of urbanization and ecological environment in Xining City from 2008 to 2017 is obtained by weighted summation of layers. The formula is [6]: 


$$
\mathrm{y}=\sum_{\mathrm{i}=1}^{\mathrm{n}} \mathrm{y}_{\mathrm{i}} \mathrm{t}_{\mathrm{i}}=\sum_{\mathrm{i}=1}^{\mathrm{n}} \mathrm{Z}_{\mathrm{i}} \mathrm{t}_{\mathrm{i}}
$$

In the formula, $y$ is the index of urbanization or comprehensive development of ecological environment; $\mathrm{yi}$ is the index of the Ith index; $\mathrm{Zi}$ is the index of the Ith index processed by the above standardized data; $t i$ is the weight of the Ith index.

\subsubsection{Quantitative model of coordination degree between urbanization and ecological environment in Xining}

Coordination is a kind of benign interrelation between two or more systems or system elements. It is a relationship of proper coordination, perfect harmony, and benign circle between systems or elements within systems. Coordination degree is a quantitative index to measure the degree of coordination between systems or elements [7]. We uses the following coordination degree model to quantify the coordination degree between urbanization and ecological environment in Xining. The model is as follows [8]:

$$
\mathrm{C}=\left\{\left(U_{1} \times U_{2}\right) \mid\left(U_{1}+U_{2}\right)\left(U_{1}+U_{2}\right)\right\} 1 / 2
$$

In the formula: $\mathrm{C}$ is the degree of coordination between urbanization and ecological environment, $\mathrm{C}$ $<(0,1)$, U1 and U2 represent the urbanization subsystem and the ecological environment subsystem respectively.

In order to more clearly reflect the coordinated development degree of urbanization and ecological environment in Xining, the coordination degree between the two systems is graded [9], as shown in Table 2.

Table 2. Coordination division and standard grade.

\begin{tabular}{c|c|c|c|c|c|c|c}
\hline coordination grade & $\begin{array}{c}\text { severe } \\
\text { disorder }\end{array}$ & $\begin{array}{c}\text { moderate } \\
\text { disorder }\end{array}$ & mild disorder & $\begin{array}{c}\text { barely } \\
\text { coordinated }\end{array}$ & $\begin{array}{c}\text { moderate } \\
\text { coordination }\end{array}$ & $\begin{array}{c}\text { good } \\
\text { coordination }\end{array}$ & $\begin{array}{c}\text { Quality } \\
\text { coordination }\end{array}$ \\
\hline coordination degree & $0 \sim 0.29$ & $0.3 \sim 0.39$ & $0.4 \sim 0.49$ & $0.5 \sim 0.59$ & $0.6 \sim 0.69$ & $0.7 \sim 0.79$ & $0.8 \sim 1.0$ \\
\hline
\end{tabular}

\section{Results}

By using formula (2), the comprehensive index values of urbanization system and ecological environment system of Xining City from 2008 to 2017 are calculated (Table

3.1Test results of comprehensive level of 3 ), and the comprehensive index changes of urbanization urbanization and ecological environment in Xining and ecological environment of Xining City in recent 10 years (Figure 1) are drawn.

Table 3. Comprehensive Development Index Table of Urbanization and Eco-environmental System in Xining City from 2008 to

\begin{tabular}{|c|c|c|c|c|c|c|c|c|c|c|}
\hline Particular year & 2008 & 2009 & 2010 & 2011 & 2012 & 2013 & 2014 & 2015 & 2016 & 2017 \\
\hline urbanization & 0.0889 & 0.1365 & 0.1070 & 0.1110 & 0.1330 & 0.2062 & 0.2894 & 0.3523 & 0.4075 & 0.4593 \\
\hline Eco-environmental System & 0.1282 & 0.1503 & 0.1519 & 0.2098 & 0.3198 & 0.3488 & 0.3160 & 0.3608 & 0.4104 & 0.3927 \\
\hline
\end{tabular}
2017.

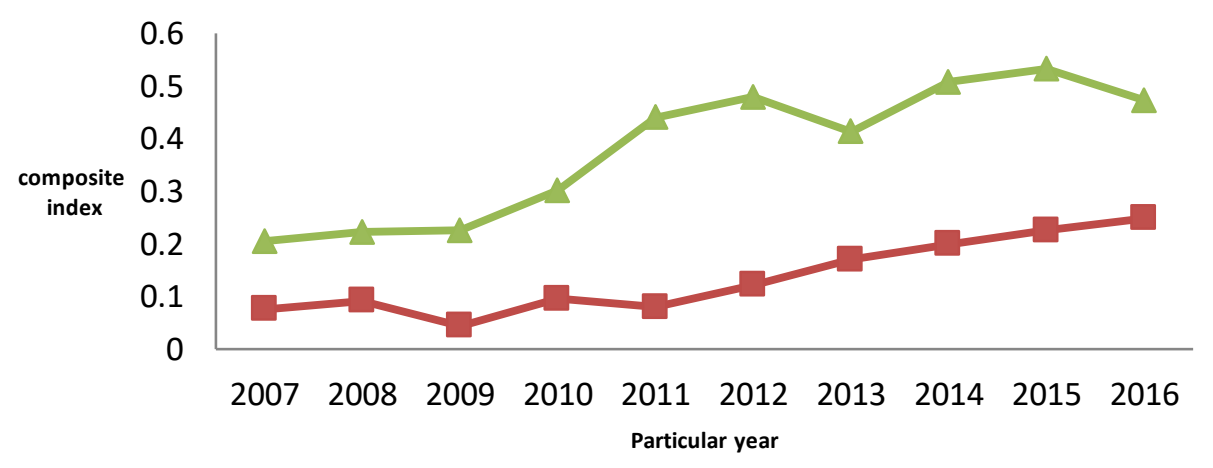

- Eco-environmental System

Figure 1. The variation of the urbanization level and the comprehensive index of eco-environment in Xining city over recent decades.

Figure 1 shows that the ecological environment of of ecological environment, with the high-speed economic Xining City has been in good condition in the past 10 years, and since 2011, the comprehensive ecological development index of Xining City has shown a dramatic growth trend. In 2016, the ecological environment development index has reached more than 0.4 , which is in line with the approval of Xining City as a national innovative pilot city. This is inseparable from the green development, paying more attention to the construction of ecological environment, strengthening the protection development.

\subsection{Calculating results of coordination between urbanization and ecological environment in Xining}

Formula (3) is used to calculate the coordination index of urbanization and ecological environment in Xining City from 2008 to 2017. At the same time, the change curve 
of coordination degree between urbanization and ecological environment in Xining City is drawn (Figure
2).

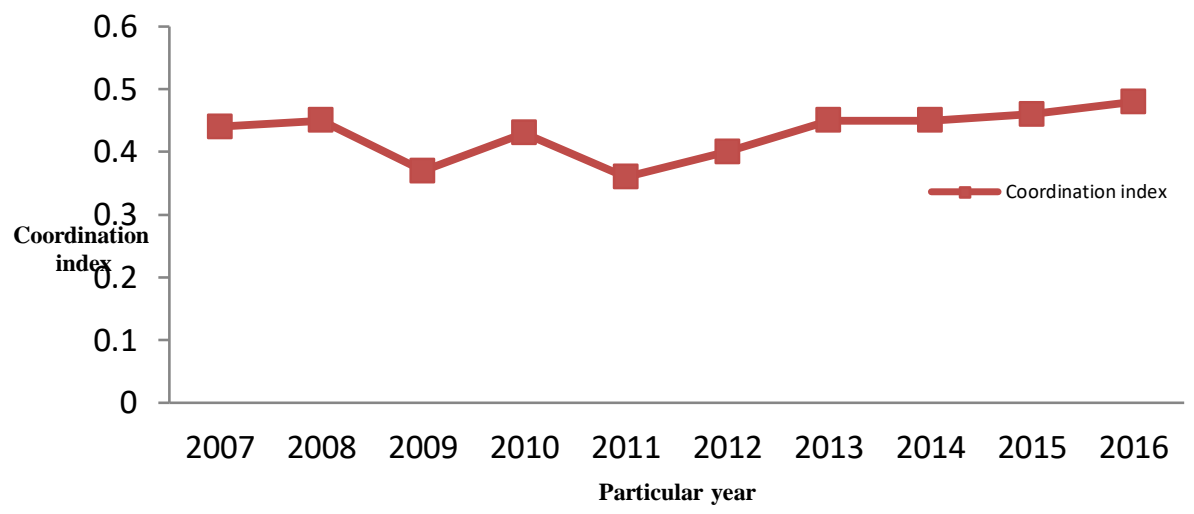

Fig.2. The changes of coordination degree of urbanization and eco-environment in Xining city over recent decades.

\section{Conclusion}

From the comprehensive index of urbanization, the urbanization level of Xining from 2008 to 2017 shows an overall upward trend. Analyzing from the comprehensive development index of ecological environment, with the fluctuation of urban development, the ecological environment quality index has been increasing sharply since 2011, which is in line with the approval of Xining as a pilot project of national innovative city. With the rapid economic development, the green development pays more attention to the construction of ecological environment. It is inseparable from strengthening the protection of ecological environment. From the perspective of coordination degree, the coordination degree between urbanization and ecological environment in Xining City has fluctuated in the past 10 years, with three years being moderately imbalanced, five years slightly imbalanced and two years barely coordinated. Generally speaking, the coordination between urbanization and ecological environment in Xining is relatively stable, but the coordination degree needs to be strengthened.

\section{Reference}

1. MENG Xiangyan, LI Weidong. Comprehensive Evaluation of Urbanization Quality in China [J]. Cooperative Economy and Science and Technology, 2016, (6): 5-10.

2. The People's Government of Xining. [OL]. http://www.xining.gov.cn/html/4931/329039.html

3. Xining Statistical Bureau.2007-2017Xining Statistical Yearbook [K].Beijing: China Statistics Press, 2017.

4. LI Jing, LI Xueming. Discussion and Evaluation of Coordination Degree between Regional Urbanization and City Ecological Environment in Dalian City [J]. Modern City Research, 2008, (2): 29-35.

5. QIAO Biao, FANG Chuanglin. The Dynamic Coupling Model of the Harmonious Development between Urbanization and Eco-environment and it's Application in Arid Area [J]. Acta Ecologica Sinica, 2005, 25(11): 3003-3009.

6. [13] WAN Nianqing, WU Guoxi, ZHANG Qianzhi. Analysis of Urbanization and Ecological Envirment Coupling in Henan Province [J] . Resource Deveoplment and Market , 2010,26(2):116-119.

7. DU Shufang, ZHEN Jianghong, WEI Aixiang. The Quantitative Analysis of the Coordination Development Between the Urbanization and Ecology Environment System in Wuhai City [J]. Journal of Inner Mongolia Normal University (Natural Science Edition), 2008, 37(5): 669-673.

8. SONG Chaoshan, MA Junjie, YANG Feng et al. Coupled System of Urbanization, Resources and Environment -A Case of Xi'an [J]. Journal of Arid Land Resources and Environment , 2010,24(5):85-90. 